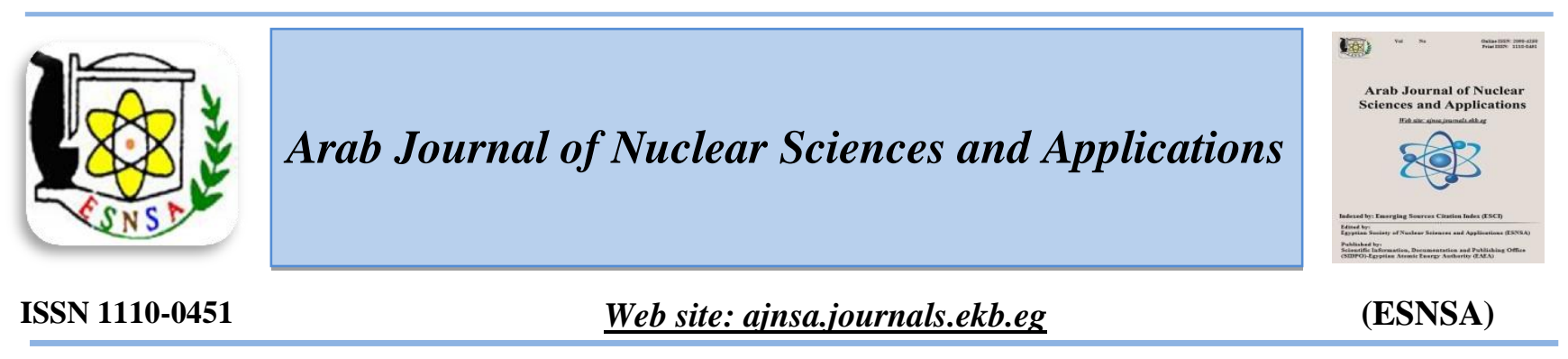

\title{
Investigation of Thermal-Hydraulic Behavior of Supercritical Water Reactor Using Thorium-Uranium Oxide Fuel $\left(\mathrm{ThO}_{2}-\mathrm{UO}_{2}\right)$
}

\author{
Adel A. Fahmy ${ }^{1}$, Adel K. El-Feky ${ }^{1}$, Hesham Elkhatib ${ }^{1}$, S. Helmy ${ }^{2}$ *, \\ Neama M. El-Sahlamy ${ }^{2}$ \\ ${ }^{1}$ Reactors Department, Nuclear Research Center, Atomic Energy Authority (AEA), Cairo, Egypt \\ ${ }^{2}$ Nuclear and Radiological Regulatory Authority (NRRA), Cairo, Egypt
}

\begin{abstract}
Received $7^{\text {th }}$ June 2018 A Super Critical Water-cooled Nuclear Reactor (SCWR) is a Generation IV concept currently being Accepted $30^{\text {st }}$ Jan. 2019 developed worldwide. Unique to this reactor type is the use of light-water coolant above its critical point. The number of SCWR components is reduced since steam separators and dryers are not required. This advantage drives down capital and maintenance costs. Safety is also increased, because a dry out phenomenon does not occur in SCW conditions; SCW remains in a single phase. A computer program by Engineering Equation Solver, (EES) has been produced for inquiry of the fuel, clad and coolant temperatures under supercritical conditions for supercritical water reactor powered by $\mathrm{ThO}_{2}-\mathrm{UO}_{2}$ mixture as a fuel. In the calculation, uniform axial heat flux and average channel were considered. The bulk fluid, clad and fuel temperatures along fuel length were obtained for supercritical pressures 26,30 and $40 \mathrm{MPa}$. Also, the $\mathrm{UO}_{2}$ percentage added to $\mathrm{ThO}_{2}$ was varied as, $4 \%$ and $10 \%$. It was found that the maximum fuel temperature reached $1917^{\circ} \mathrm{C}$ for a pressure of $26 \mathrm{MPa}$ and $1896^{\circ} \mathrm{C}$ for a pressure of 30 $\mathrm{MPa}$ in case of $4 \% \mathrm{UO}_{2}$. However, the maximum temperature of the fuel was $1915{ }^{\circ} \mathrm{C}$ for a pressure of $26 \mathrm{MPa}$ and $1894^{\circ} \mathrm{C}$ for a pressure of $30 \mathrm{MPa}$ in case of $10 \% \mathrm{UO}_{2}$, which is surpasses the industry limit of $1850{ }^{\circ} \mathrm{C}$.
\end{abstract}

Keywords - (Th, U) $\mathrm{O}_{2}$ pellets, Thermal conductivity, Thermal hydraulic, Supercritical water reactor

\section{Introduction}

Thorium oxide $\left(\mathrm{ThO}_{2}\right)$ has recently attracted much attention as a nuclear fuel since it is proliferation resistant and the amount of uranium oxide is limited.

Thorium is not fissile, but can be converted into U233 which is a fissionable isotope [1]. The behavior of nuclear fuel through irradiation is mainly dependent on its physicochemical properties and their change in temperature and burn-up. Other important thermo-physical properties to be considered are the melting point and density of the fuel. Thorium and uranium oxide fuels utilized in nuclear reactors have very high melting point, but they are of low density and they suffer from poor thermal conductivity [2].

\section{Thermal conductivity of $\mathrm{ThO}_{2}-\mathrm{UO}_{2}$ fuel}

It is well known that the thermal conductivity of $\mathrm{ThO}_{2}$ is $50 \%$ higher than that of $\mathrm{UO}_{2}$ over a considerable temperature range [2]. Berman et al. [3] suggested a systematic attempt to correlate thermal conductivity, temperature, and

Corresponding author: adelalyan@yahoo.com

DOI: 10.21608/ajnsa.2019.4062.1094

(C) Scientific Information, Documentation and Publishing Office (SIDPO)-EAEA 
composition for $\mathrm{ThO}_{2}-\mathrm{UO}_{2}$ system in the early 1970s. Belle and Berman [4] modernized the thermal conductivity correlation to $3126.85 \mathrm{o}^{\mathrm{C}}$ by making use of the enthalpy data.

\section{Melting point}

A very important thermo-physical property to be considered for an engineering material, such as nuclear fuel, is the melting point. The onset of melting at the centerline of the fuel rod has been extensively accepted as an upper limit to the allowable thermal rating of nuclear fuel elements [4]. The melting point must be taken into account when considering a new fuel, as it limits the power that can be extracted from the fuel element. The knowledge of the melting point is also important in the fabrication of chemically homogeneous pellets like thoria-urania. $\mathrm{ThO}_{2}$, and $\mathrm{UO}_{2}$, have high melting points $3386.85,2826.85 \mathrm{o}^{\mathrm{C}}$ relatively and they have a low diffusion coefficient at normal sintering temperatures [5].

Figure (1) shows the fuel bundle design with the large diameter center rod, so-called Variant-20 bundle [7], which is used in the current analysis. The central rod has an outside diameter of $20 \mathrm{~mm}$ and is assumed to be unheated and the heated length is $5.772(\mathrm{~m})$. The remaining 42 elements have the outside diameter of $11.5 \mathrm{~mm}$, the hydraulic equivalent diameter of the bundle is 7.83 mm.

\section{MATHEMATICAL MODEL}

The following are the recommended equations for the fuel thermal conductivity $(\mathrm{K})$ as a function of temperature $(\mathrm{T}, \mathrm{K})$ which are valid from 873 to 1873 (K) for $0 \%, 4 \%, 6 \%$ and $10 \%$, respectively, of $\mathrm{UO}_{2}$, [8].

$\mathrm{K}\left[\mathrm{ThO}_{2}\right]=1 /(-0.03198+2.03559 \times 10-4 \times \mathrm{T})$

$\mathrm{K}\left[\mathrm{Th}_{0.96}, \mathrm{U}_{0.04}\right] \mathrm{O}_{2}=1 /\left(-0.04505+2.06241 \times 10^{-4} \times\right.$ $\mathrm{T})$

$\mathrm{K}\left[\mathrm{Th}_{0.94}, \mathrm{U}_{0.06}\right] \mathrm{O}_{2}=1 /\left(-0.02884+2.6034 \times 10^{-4} \times\right.$ T)

$\mathrm{K}\left[\mathrm{Th}_{0.90}, \mathrm{U}_{0.10}\right] \mathrm{O}_{2}=1 /\left(-0.04334+2.519 \times 10^{-4} \times\right.$ T)

Belle and Berman [4] reported the following equation for the thermal conductivity of $100 \%$ dense $\mathrm{ThO}_{2}$ in the temperature range of 298-2950 $(\mathrm{K})$,

$\mathrm{K}\left[\mathrm{ThO}_{2}\right]=(0.0213+1.597 \times 10-4 \times \mathrm{T})^{-1}$

Belle and Berman [4] first obtained an expression for thermal diffusivity up to $2950(\mathrm{~K})$ as: $\alpha\left[\mathrm{ThO}_{2}\right]\left(\mathrm{m}^{2} / \mathrm{s}\right)=(-34191.1+561.28 \times \mathrm{T})^{-1}(6)$
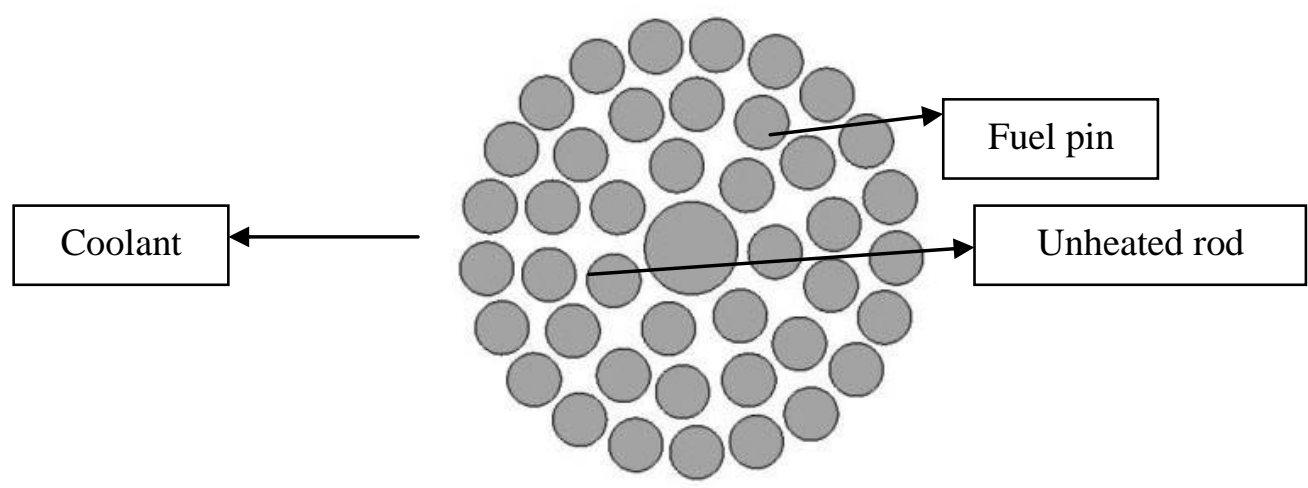

Figure (1): Fuel bundle geometry 43 elements, Variant-20, center element OD $20 \mathrm{~mm}$ and the rest - $11.5 \mathrm{~mm}$ [6] 


\section{Temperature distribution in the axial direction}

The following equation represents the power with respect to the axial position or heat-flux ratio:

$$
\text { Power ratio }=\dot{\mathrm{q}}_{\text {loc }}^{\prime}=\frac{\dot{\mathrm{q}}_{\text {loc }}}{\dot{\mathrm{q}}_{\text {ave }}}
$$

Where, $\mathrm{q}_{\text {loc }}$ is local heat flux, $\mathrm{W} / \mathrm{m}^{2}$ and $\mathrm{q}_{\text {ave }}$ is average heat flux $\mathrm{W} / \mathrm{m}^{2}$

$$
\dot{q}_{\text {ave }}=\frac{\dot{Q}_{C h}}{A_{h}}
$$

Where,

$$
A_{h}=\pi l_{h}\left(N_{c} D_{c}+N_{i r} D_{i r}+N_{m r} D_{m r}+N_{o r} D_{o r}\right)
$$

$$
\begin{aligned}
& \dot{q}_{l o c}^{\prime}=a_{0}+a_{1} x^{1}+a_{2} x^{2}+a_{3} x^{3}+a_{4} x^{4}+ \\
& \dot{Q}_{l o c_{x}}^{\prime}=P_{h} \int_{0}^{x} \dot{q}_{l o c} d x \\
& \dot{Q}_{l o c_{x}}^{\prime}=P_{h} q_{\text {ave }} \int_{0}^{x} q_{l o c}^{\prime} d x \\
& P_{h}=\pi\left(N_{\text {ir }} D_{\text {ir }}+N_{m r} D_{m r}+N_{o r} D_{o r}\right)
\end{aligned}
$$$$
\int_{0}^{x} \dot{q}_{l o c}^{\prime} d x=a_{0} \frac{1}{1} x+a_{1} \frac{1}{2} x^{2}+a_{2} \frac{1}{3} x^{3}+a_{3} \frac{1}{4} x^{4}+a_{4} \frac{1}{5} x^{5}+a_{5} \frac{1}{6} x^{6}+a_{6} \frac{1}{7} x
$$

The polynomial coefficients $\left(a_{0}-a_{6}\right)$ are shown in Table (1) [9]

Channel power was calculated through integration of polynomial equation as seen in the following equation:

$\dot{Q}_{c h}=P_{h} q_{a v e} \int_{0}^{5.772} q_{\text {loc }}^{\prime} d x$

Now Eq. (12) allows calculating the heat output at any axial location. Power per each millimeter increment, along the heated length was calculated by the following equations:

$$
\dot{Q}_{l o c, m m}=\dot{Q}_{l o c, x+1}-\dot{Q}_{l o c, x}
$$

$$
\dot{q}_{l o c, x}=\frac{\dot{Q}_{l o c, m m}}{A_{m m}}
$$

\section{Outer-sheath temperature}

The outer - sheath temperature was obtained based on the corresponding bulk-fluid temperature $(\mathrm{Tb})$, i.e., in the same cross section, and HTC. The HTC was calculated according to the Bishop et al. correlation (1964). The correlation of Bishop et al. is suitable for a pressure range from 22.8 to 27.6 $\mathrm{MPa}$, bulk-fluid temperature range - between 282 and $527^{\circ}$, and heat flux range - between 0.31 and $3.46 \mathrm{MW} / \mathrm{m}^{2}$, which corresponds to the generic SCWR operating conditions [10].

$$
N u_{x}=0.0069 R e_{x} \operatorname{Pr}_{x}^{0.66}\left(\frac{\rho_{w}}{\rho_{b}}\right)_{x}^{0.43}\left(1+2.4 \frac{D_{h y}}{x}\right)
$$

The correlation of Swenson et al. was developed using a pressure range of $22.8-41.4 \mathrm{MPa}$, and mass flux of $542-2150 \mathrm{~kg} / \mathrm{m}^{3}$. s [11]. The correlation uses the wall temperature to calculate thermo physical properties and is shown in the following equation:

$$
\begin{aligned}
& N u_{x}=0.00459 \operatorname{Re}_{w}^{0.923} \operatorname{Pr}_{w}^{0.613}\left(\frac{\rho_{w}}{\rho_{b}}\right)^{0.231} \\
& D_{\text {hy }}=\frac{4 A_{\text {flow }}}{P_{\text {wetted }}} \\
& A_{\text {flow }}=A_{\text {pt }}-A_{\text {block }} \\
& P_{\text {wetted }}=\pi
\end{aligned}
$$

$\left(N_{c} D_{c}+N_{i r} D_{i r}+N_{m r} D_{m r}+N_{o r} D_{o r}+D_{p t}\right)$

The outer-sheath temperature can be calculated according to the following equation [9].

$T_{o, s h}=\frac{\dot{q}}{H T C}+T_{b}$

Inner-sheath temperature

The inner- sheath temperature can be calculated according to the following equation [9].

$$
T_{i, s h}=\frac{\dot{Q}_{s h, x} \ln \left(\frac{r_{o, s h}}{r_{i, s h}}\right)}{2 \pi k_{s h}}+T_{o, s h}
$$


ADEL A. FAHMY et al.

Table (1): Polynomial Coefficients for Eqs. 10 -14

\begin{tabular}{|l|l|l|l|l|l|l|l|}
\hline Cosine Profile & $\mathrm{a}_{\mathrm{o}}$ & $\mathrm{a}_{1}$ & $\mathrm{a}_{2}$ & $\mathrm{a}_{3}$ & $\mathrm{a}_{4}$ & $\mathrm{a}_{5}$ & \multicolumn{1}{|c|}{$\mathrm{a}_{6}$} \\
\hline Normal & 0.0752 & 0.8888 & 0.1519 & -0.3016 & 0.1121 & $0.0182-$ & $1.0758 \mathrm{e}-3$ \\
\hline Upstream & 0.0166 & 1.6104 & -0.2439 & -0.3484 & 0.1717 & -0.0296 & $1.7490 \mathrm{e}-3$ \\
\hline Downstream & 0.0747 & 0.7558 & 0.3514 & -0.5203 & 0.2024 & 0.0326 & $1.8439 \mathrm{e}-3$ \\
\hline
\end{tabular}

The correlation of Swenson et al. was developed using a pressure range of $22.8-41.4 \mathrm{MPa}$, and mass flux of $542-2150 \mathrm{~kg} / \mathrm{m}^{3}$. s [11]. The correlation uses the wall temperature to calculate thermo physical properties and is shown in the following equation:

$$
N u_{x}=0.00459 R e_{w}^{0.923} \operatorname{Pr}_{w}^{0.613}\left(\frac{\rho_{w}}{\rho_{b}}\right)^{0.231}
$$

$D_{\text {hy }}=\frac{4 A_{\text {flow }}}{P_{\text {wetted }}}$

$A_{\text {flow }}=A_{\text {pt }}-A_{\text {block }}$

$P_{\text {wetted }}=\pi$

$\left(N_{c} D_{c}+N_{i r} D_{i r}+N_{m r} D_{m r}+N_{o r} D_{o r}+D_{p t}\right)$

The outer-sheath temperature can be calculated according to the following equation [9].

$T_{o, s h}=\frac{\dot{q}}{H T C}+T_{b}$

Inner-sheath temperature

The inner- sheath temperature can be calculated according to the following equation [9].

$T_{i, s h}=\frac{\dot{Q}_{s h, x} \ln \left(\frac{r_{o, s h}}{r_{i, s h}}\right)}{2 \pi k_{s h}}+T_{o, s h}$

Fuel centerline temperature
The aim of this investigation is to be sure that the fuel $\left(\mathrm{ThO}_{2}-\mathrm{UO}_{2}\right)$ centerline temperature $\left(\mathrm{T}_{\mathrm{b}}\right)$ will be below the industry accepted limit of $1850{ }^{\circ} \mathrm{C}$. The following correlations were used for the fuel centerline temperature calculations [9]:

$T_{f c}=\frac{\dot{e}_{g e n, m m} \times r_{i, s h}^{2}}{4 k_{f u e l}}+T_{i, s h}$

$\dot{e}_{g e n, m m}=\frac{\dot{Q}_{l o c, m m}}{D_{i, s h}^{2} \times \pi(0.001 \mathrm{~m})}$

\section{Bulk-fluid temperature}

The initial step in the heat-transfer analysis is to determine the bulk-fluid temperature profile along the heated length, which was obtained by the heatbalance method. The inlet bulk-fluid enthalpy $\left(\mathrm{h}_{\mathrm{x}}\right)$ was obtained based on the inlet temperature of $350^{\circ} \mathrm{C}$ and constant pressure.

$$
h_{x}=\frac{Q_{l o c, m m}}{\dot{m}}+h_{x-1}
$$

Calculation of the heat transfer coefficient

The Reynolds number is expressed as:

$R e=\frac{D_{h y} \times v}{\gamma}$

$\gamma=\frac{\mu}{\rho}$

$N u_{x}=\frac{\mathrm{HTC} \times \mathrm{D}_{\mathrm{hy}}}{\mathrm{k}_{\mathrm{f}}}$ 
Table (2): Selected parameters of proposed SCWR fuel channels. [12,13]

\begin{tabular}{|l|c|}
\hline \multicolumn{1}{|c|}{ Parameters } & Value \\
\hline Max cladding temperature (design value), & $850^{\circ} \mathrm{C}$ \\
\hline Max fuel centerline temperature (industry accepted limit) & $1850^{\circ} \mathrm{C}$ \\
\hline Heated fuel channel length & $5.772 \mathrm{~m}$ \\
\hline Number of fuel rod per bundle & 43 \\
\hline Number of heated fuel rods & 42 \\
\hline Number of unheated fuel rods & 1 \\
\hline Diameter of heated fuel rods (\# of rods) & $11.5(35) \& 13.5(8) \mathrm{mm}$ \\
\hline Diameter of unheated fuel rod & $20 \mathrm{~mm}$ \\
\hline Hydraulic equivalent diameter of fuel channel & $7.83 \mathrm{~mm}$ \\
\hline Heated area of fuel channel & $8.76 \mathrm{~m}^{2}$ \\
\hline Flow area of fuel channel & $3729 \mathrm{~mm}^{2}$ \\
\hline
\end{tabular}

temperature reaches $609.9,577.7$ and $512{ }^{\circ} \mathrm{C}$ at 26 ,

\section{Results}

In this part, a summary of the results of the steady state calculation of the fuel, clad and coolant temperatures are given. The bulk fluid, clad and fuel temperatures along fuel length were obtained for supercritical pressures 24, 30 and $40 \mathrm{MPa}$. Also, the $\mathrm{UO}_{2}$ percentage added to $\mathrm{ThO}_{2}$ was varied, $4 \%$ and $10 \%$.

Figure (2) Shows the fuel centerline temperature of thorium-uranium oxide fuel containing $4 \% \mathrm{UO}_{2}$ for different supercritical pressures. It is clear that the temperature surpasses the industry limit of $1850{ }^{\circ} \mathrm{C}$. The fuel centerline temperature decreases with increasing the supercritical temperature due to increasing in the heat transfer coefficient reaching to the values 7419,8157 , and $10474 \mathrm{~kW} / \mathrm{m} 2{ }^{\circ} \mathrm{C}$ associated with the supercritical pressures 26,30 and $40 \mathrm{MPa}$ respectively.

Figure (3) depicts the clad temperature distribution at different supercritical pressures for the fuel containing $4 \% \quad \mathrm{UO}_{2}$. The maximum clad temperature reaches to $848,797.3$ and $688.3^{\circ} \mathrm{C}$ which is associated with the supercritical pressures of 26, 30 and $40 \mathrm{MPa}$ respectively. The clad temperature decrease is due to the increase of the heat transfer coefficient with increasing of supercritical pressures.

Figure (4) illustrates the relation of the reactor coolant temperature with the heated length of the fuel for different supercritical pressures. The coolant temperature decreases with the increase of

the supercritical pressure due to the increase of coolant specific heat, The maximum outlet
30 and $40 \mathrm{MPa}$ respectively.

Figure (5) shows the fuel centerline temperature at $10 \% \mathrm{UO}_{2}$, for different supercritical pressures, where it is clear that the temperature surpasses the industry limit of $1850{ }^{\circ} \mathrm{C}$. The fuel centerline temperature decreases with increasing the supercritical temperature due to increasing in the heat transfer coefficient, as seen in Figure (5), but in this case the maximum fuel temperatures are lower than the maximum fuel temperature in case of $4 \% \mathrm{UO}_{2}$, due to increasing of fuel conductivity. For $10 \% \mathrm{UO}_{2}$, fuel, Figure (6) describes the clad temperature distribution at different supercritical pressures. The clad temperature decreasing is due to increasing of the heat transfer coefficient with increasing of supercritical pressures.

Figure (7) reavels the effect of the supercritical pressure on the reactor coolant temperature along the heated length of the fuel. The coolant temperature found decreases with increases of the supercritical pressure due to increasing of coolant specific heat.

Figure (8) shows that there is a good match between the present work and that reported by Lisa Grande et al. [9] for fuel clad and coolant temperatures, and shows that both of fuel temperature curves surpass the industry limit which is $1850{ }^{\circ} \mathrm{C}$ and that the clad temperature is about to touch the clad temperature limit which is $850{ }^{\circ} \mathrm{C}$. It is also noticed that the clad temperature for the present work at any heated length is higher than that early reported [9], where the fuel clad materials used is Inconel-600, whereas model 304 st-steel was used as a cladding material in the present investigation model. It is known that the thermal conductivity of the Inconel-600 is higher than that of SS-304. 


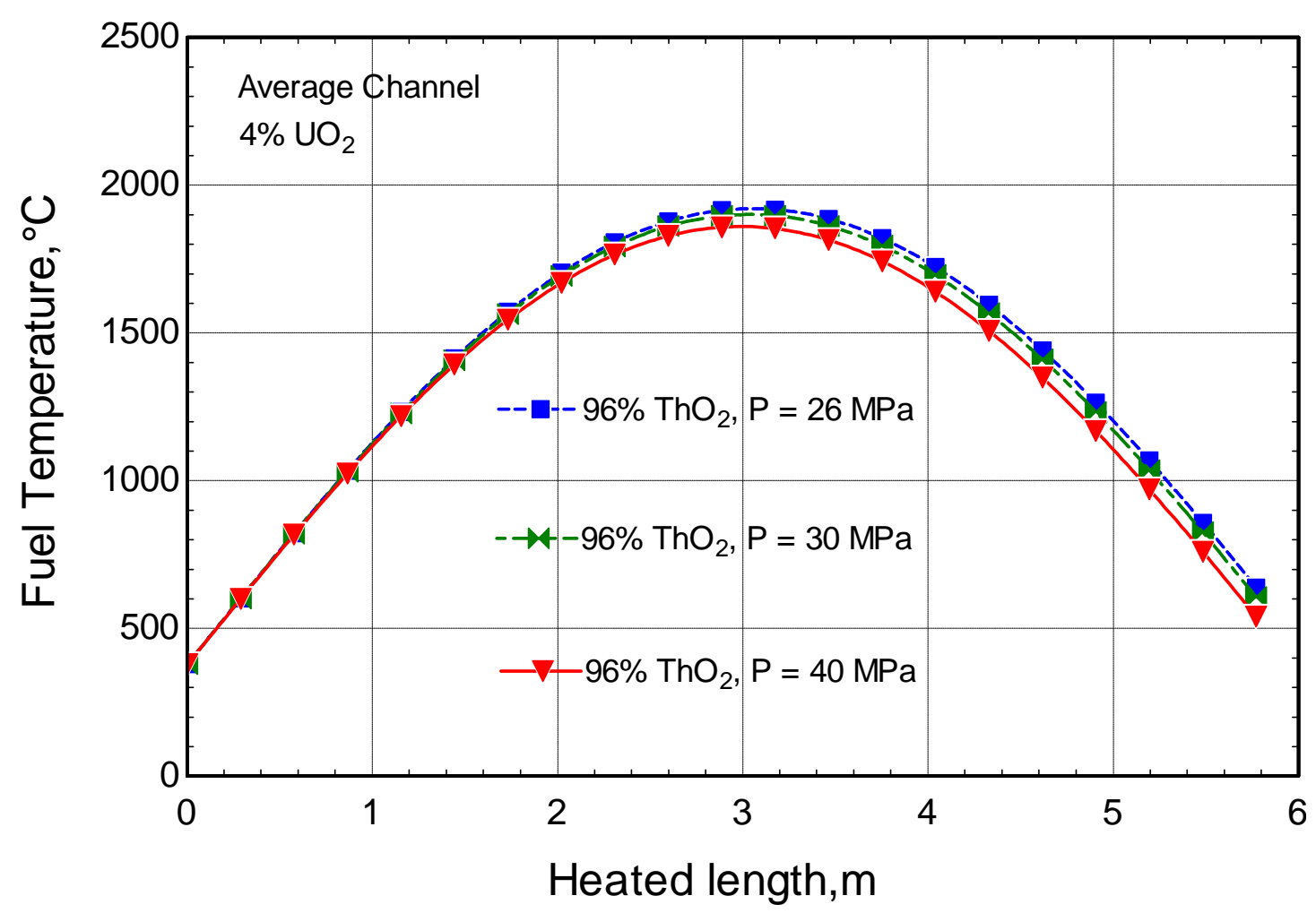

Figure (2): Fuel temperature distribution at $4 \% \mathrm{UO}_{2}$ for different supercritical pressures

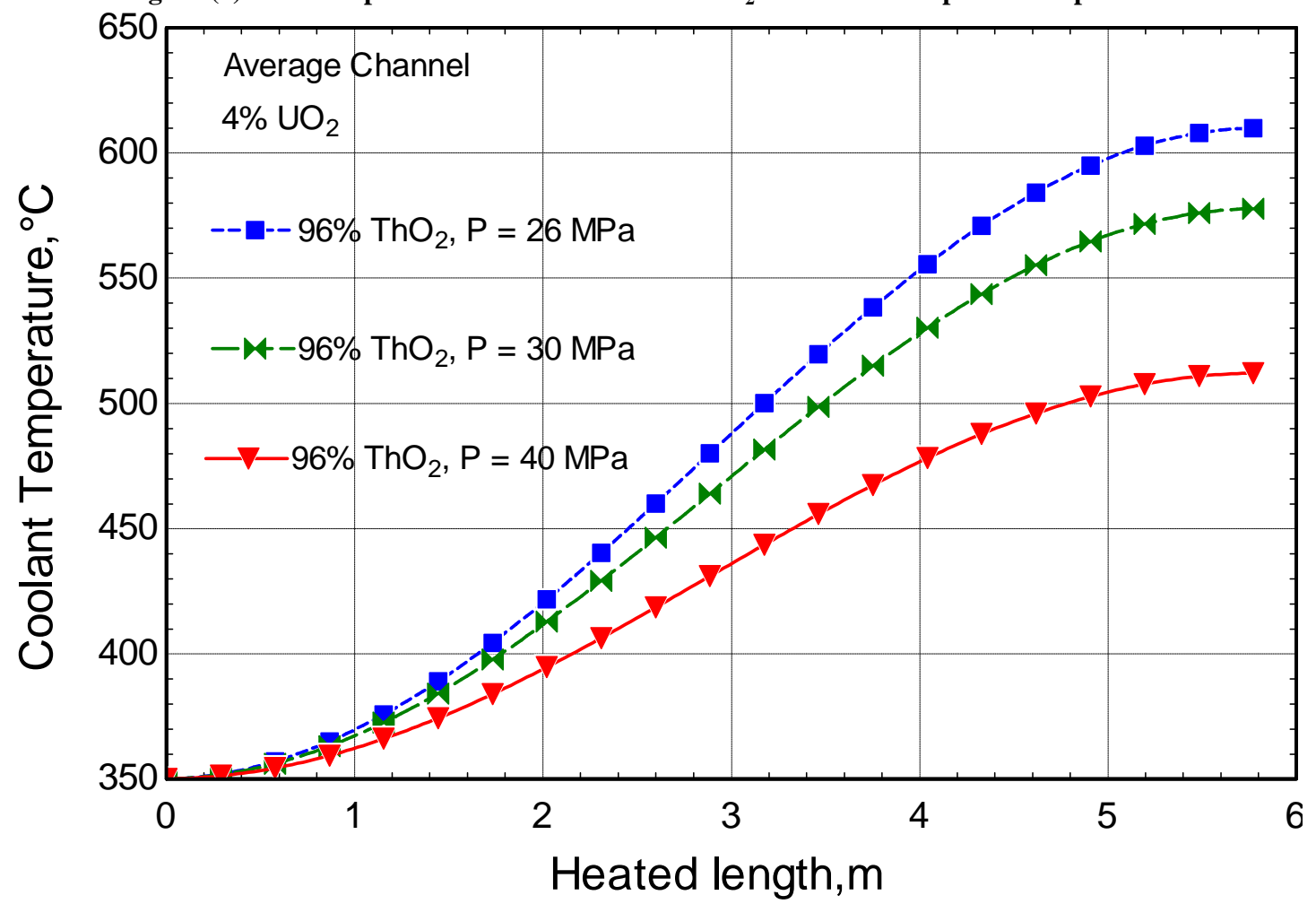

Figure (3): Clad temperature distribution at $4 \% \mathrm{UO}_{2}$ for different supercritical pressures 


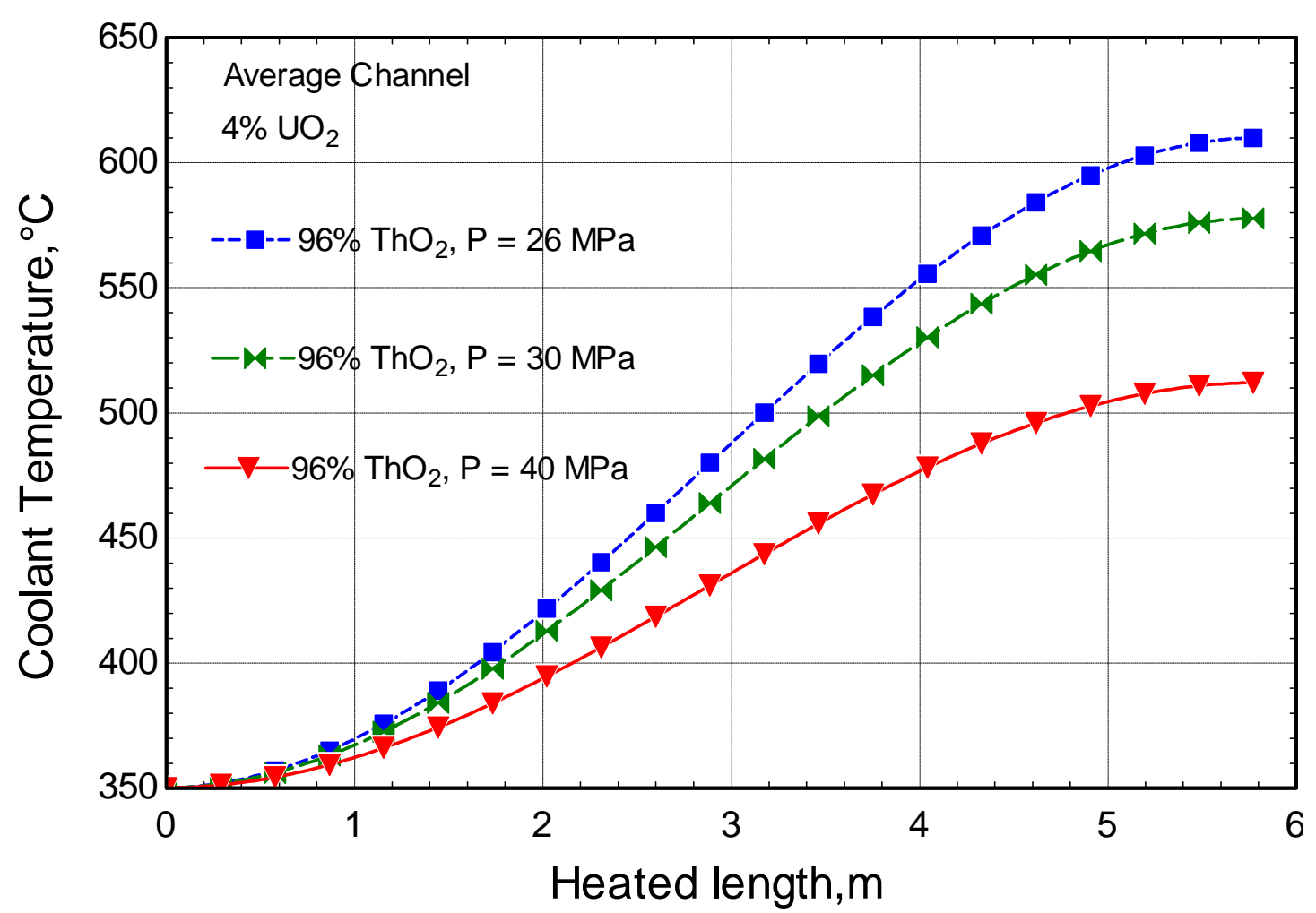

Figure (4): Coolant temperature distribution at $4 \% \mathrm{UO}_{2}$ for different supercritical pressures

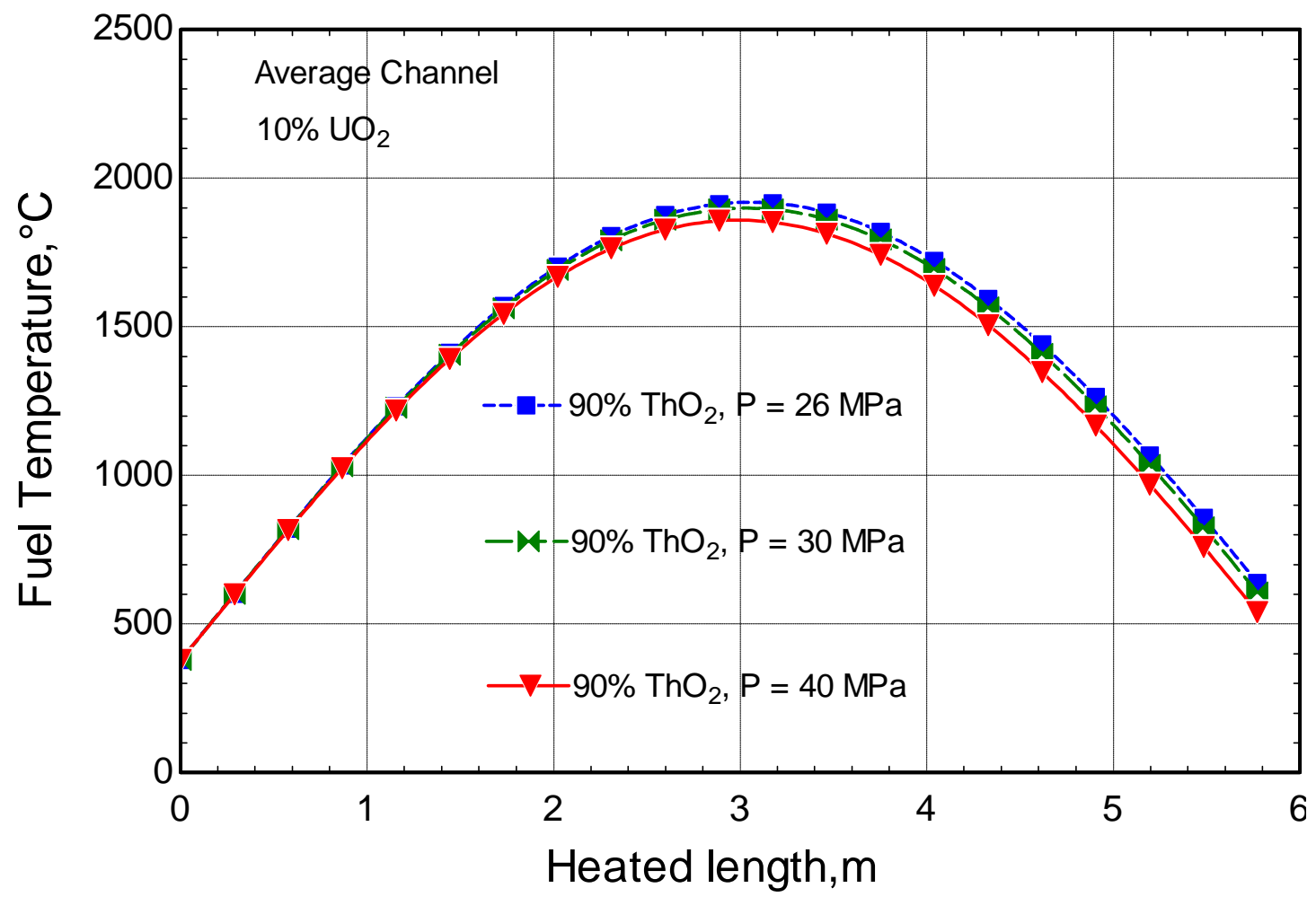

Figure (5): Fuel temperature distribution at $10 \% \mathrm{UO}_{2}$ for different supercritical pressures 


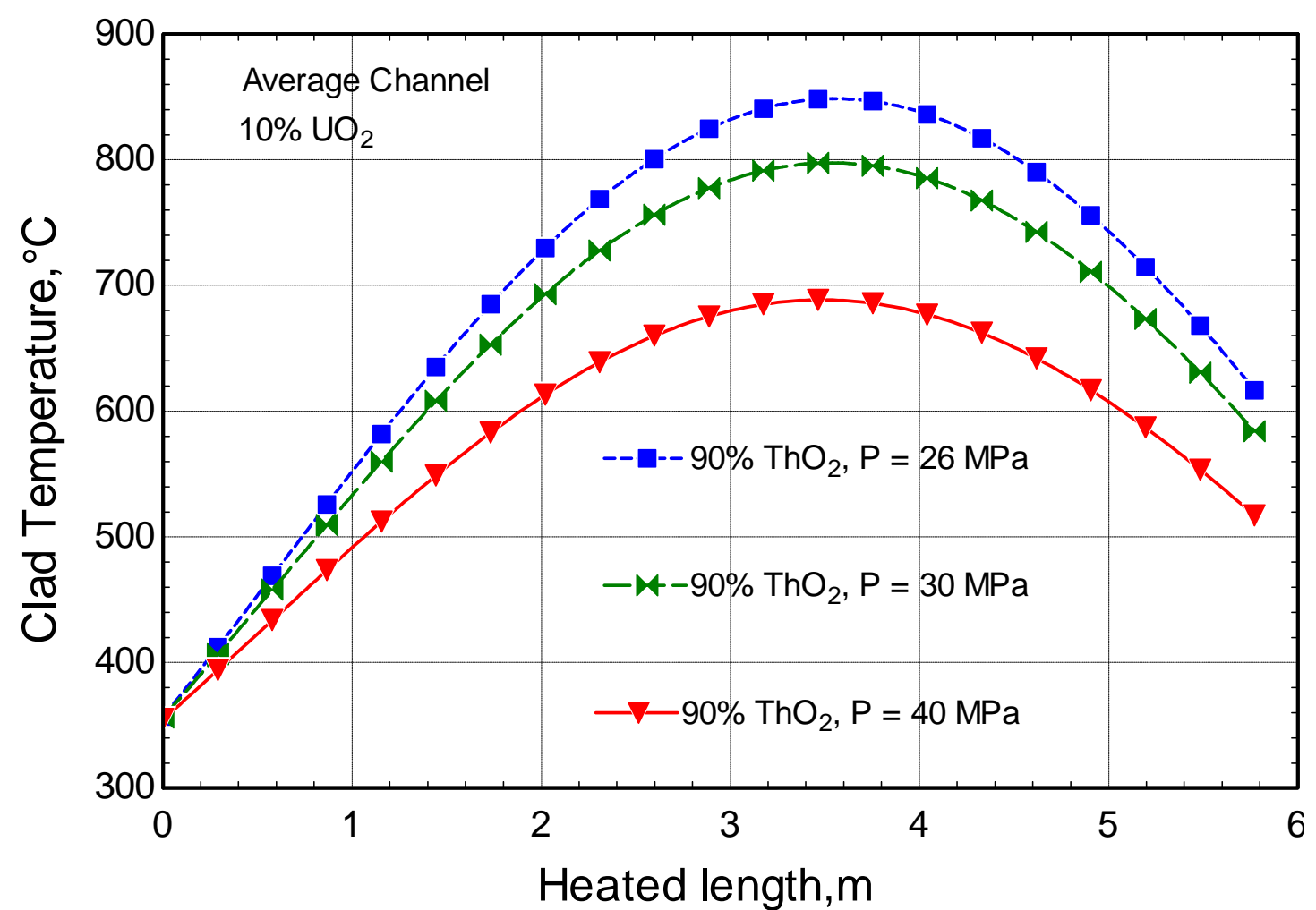

Figure (6): Clad temperature distribution at $10 \% \mathrm{UO}_{2}$ for different supercritical pressures

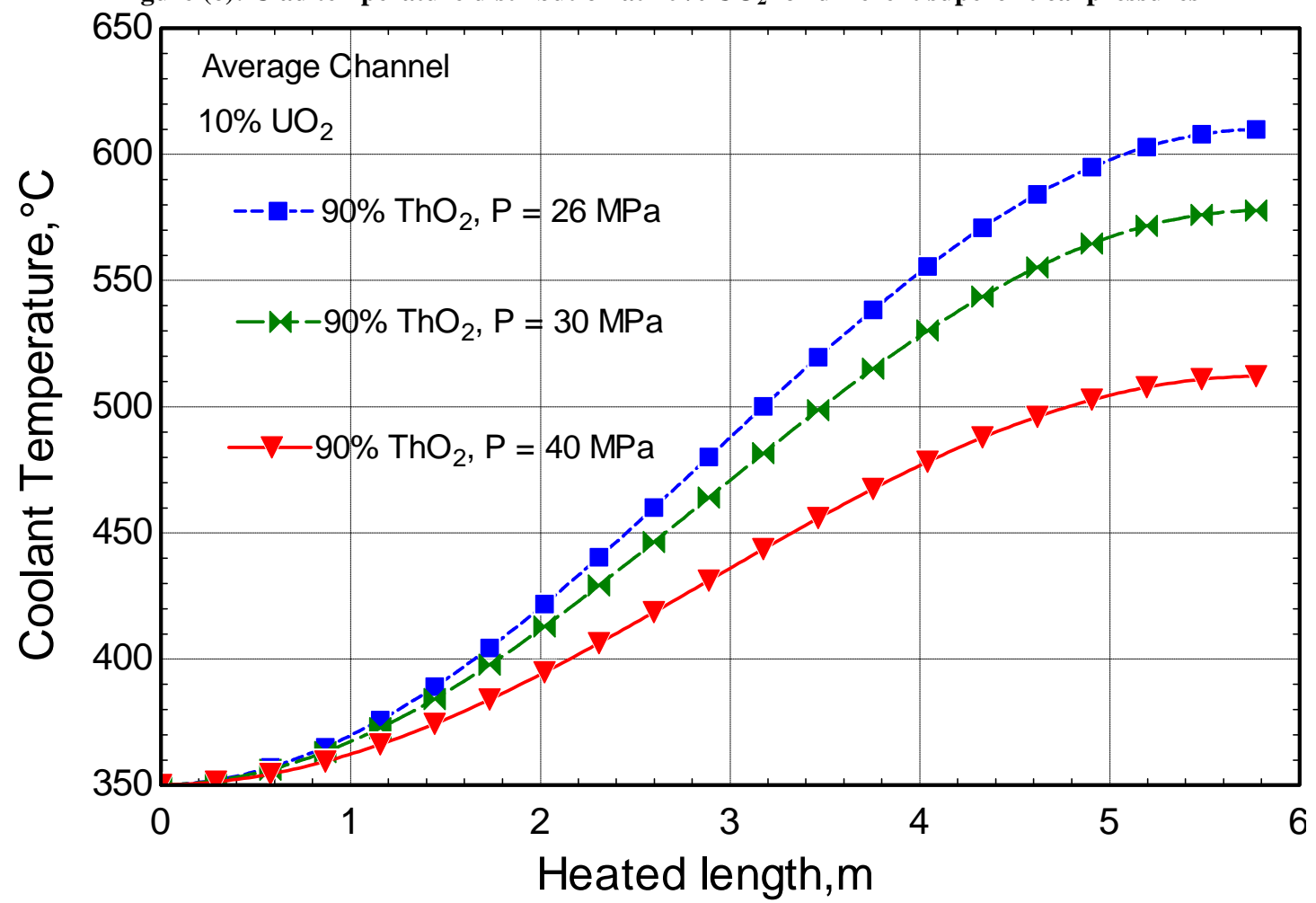

Figure (7): Coolant temperature distribution at $10 \% \mathrm{UO}_{2}$ for different supercritical pressures 


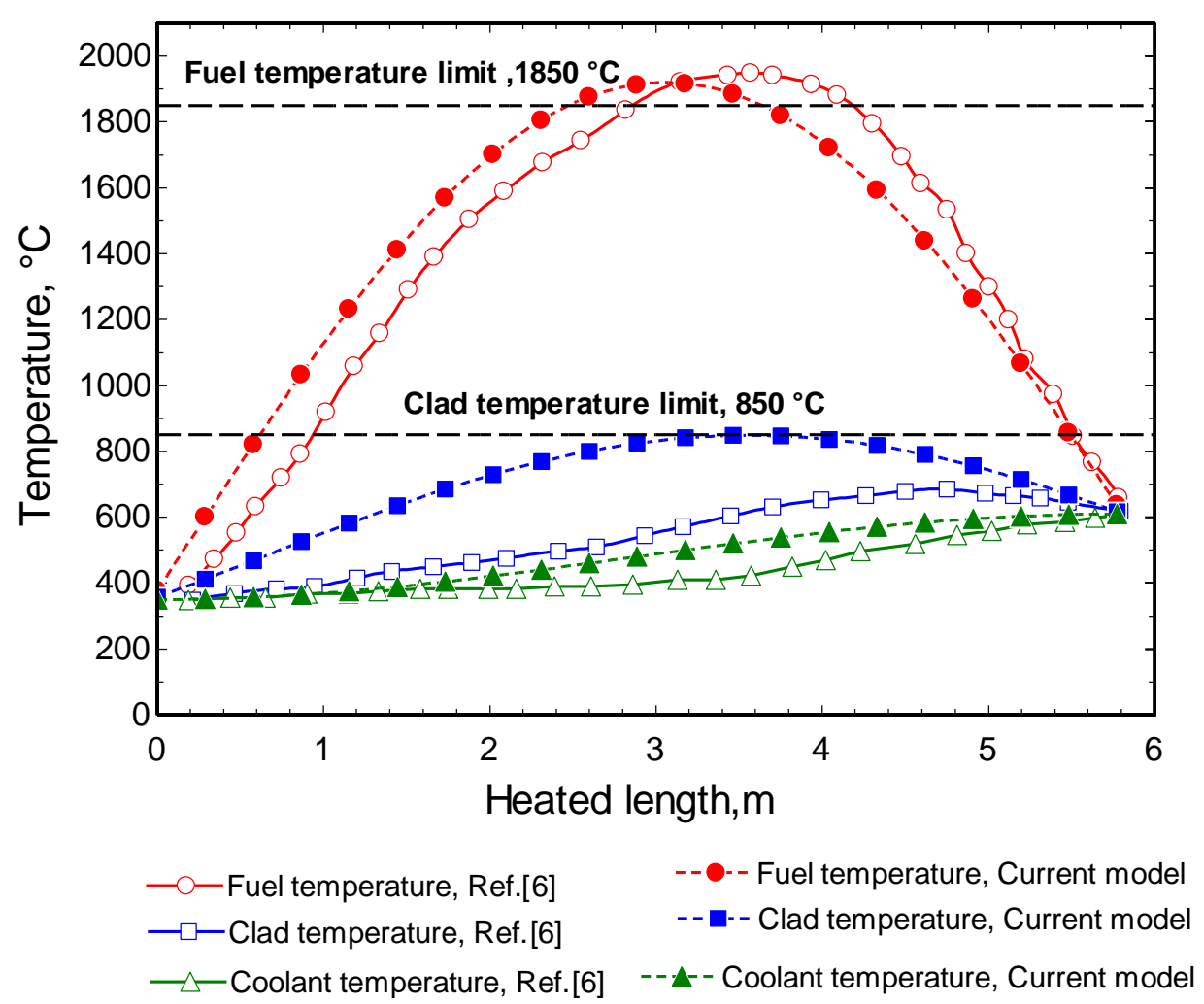

Figure (8): Comparison between the present work, Ref. [6]

\section{Conclusion}

$\mathrm{C}_{\mathrm{p}}$

For the investigated variable parameters, the fuel pressure, J/kg. K.

centerline temperature surpassed the industry limit HTC Heat Transfer Coefficient, $\mathrm{W} / \mathrm{m}^{2} . \mathrm{K}$.

temperature, which is $1850{ }^{\circ} \mathrm{C}$ in case of $4 \% \mathrm{UO}_{2}$ and $\mathrm{D}$

$10 \% \mathrm{UO}_{2}$ for all supercritical pressures. The clad $\mathrm{h}$ temperature also exceeded the clad industry limit $\dot{e}_{g e n}$ which is $850{ }^{\circ} \mathrm{C}$. However, on the other hand, as the supercritical pressure increased, the fuel, clad and $\mathrm{k}$ coolant temperatures have been found to decrease. $\dot{m}$ Adding of $\mathrm{UO}_{2}$ to the thoria, resulted in a high fuel temperature exceeding the industry limit. Hence using $\mathrm{Nu}$ $\mathrm{UO}_{2}$ as a nuclear fuel might not be the correct choice $\mathrm{p}$ for supercritical water-cooled reactors (SCWRs). P Thoria has also a high melting point which is very $\operatorname{Pr}$ important in terms of fuel failures and release of $Q$ fission product, this high melting point increases the $\dot{Q}$ durability and safety during normal and abnormal $\dot{q}$ reactor operations. Using Inconel-600 seems to be the best sheath material choice compared to 304 st-steel ${ }^{\prime}$ because of its higher mechanical strength at high $r$ pressures and temperatures.

\section{Nomenclature}

$\mathrm{a}_{\mathrm{i}}$

A

$\mathrm{A}_{\text {flow }}$
Polynomial coefficient.

area, $\mathrm{m}^{2}$.

flow area, $\mathrm{m}^{2}$.

diameter, $\mathrm{m}$.

enthalpy, $\mathrm{J} / \mathrm{kg}$.

volumetric heat flux, $\mathrm{W} / \mathrm{m} 3$.

thermal conductivity, W/m K.

length, $\mathrm{m}$.

mass-flow rate, $\mathrm{kg} / \mathrm{s}$.

Nusselt number, dimensionless.

perimeter, $\mathrm{m}$.

pressure, $\mathrm{Pa}$.

Prandtl number, dimensionless.

heat transfer, J.

heat transfer rate, $\mathrm{W}$.

heat flux, W/m2.

power ratio.

radius, $\mathrm{m}$.

Reynolds number, dimensionless.

$\begin{array}{ll}\mathrm{Re} & \text { Reynolds number, } \\ \mathrm{T} & \text { temperature, }{ }^{\mathrm{O}} \mathrm{C} .\end{array}$

SCWR Super Critical Water Reactor.

\section{Greek Symbols}

$\mu$

$v$

$\rho$ dynamic viscosity, $\mathrm{Pa} \cdot \mathrm{s}$. kinematic viscosity, $\mathrm{m}^{2} / \mathrm{s}$. density, $\mathrm{kg} / \mathrm{m}^{3}$. 


$\begin{array}{ll}\begin{array}{ll}\text { Subscripts } \\ \text { ave }\end{array} & \begin{array}{l}\text { average. } \\ \text { b }\end{array} \\ \text { block } & \begin{array}{l}\text { cross sectional area blocking fluid } \\ \text { flow. }\end{array} \\ \text { c } & \begin{array}{l}\text { center. } \\ \text { channel. }\end{array} \\ \text { fc } & \text { fuel centerline. } \\ \text { flow } & \text { cross sectional flow area. } \\ \text { fuel } & \text { fuel. } \\ \text { hy } & \text { hydraulic equivalent. } \\ \text { i } & \text { inner. } \\ \text { ir } & \text { inner ring. } \\ \text { loc } & \text { local. } \\ \text { mm } & \text { per millimeter increment. } \\ \text { o } & \text { outer. } \\ \text { or } & \text { outer ring. } \\ \text { pt } & \text { pressure tube. } \\ \text { sh } & \text { sheath. } \\ \text { w } & \text { wall. } \\ \text { wetted } & \text { wetted. } \\ \text { x } & \text { axial location along heated length. }\end{array}$

\section{References}

1- Ki Won Kang, Jae Ho Yang, Keon Sik Kim, Kun Woo Song, Chan Bock Lee, and Youn Ho Jung,“(Th,U) O2 Pellets : Fabrication and Thermal Properties," Journal of the Korean Nuclear Society,(35)299 - 308,(2003).

2- T. R. GovindanKutty, Joydipta Banerjee and Arun Kumar, "Thermophysical Properties of Thoria-based Fuels," Springer International Publishing AG, London, 11-70, (2013)

3- Berman RM, Tully TS, Bell J, Goldberg I., "The thermal conductivity of polycrystalline thoria and thoria-urania solution,"LMWR Development Program WAPD-TM-908, (1972);https://inis.iaea.org/search/search.aspx?o rig_q=RN:4063316

4- Belle J, Berman RM, "Thorium dioxide: properties and nuclear applications," Naval Reactors Office, United State Department of
Energy,(1984);https://inis.iaea.org/search/search .aspx?orig_q=RN:16071971

5- Olson GL, McCardell RK, Illum DB, Fuel summary report: "shippingport light water breeder reactor" Idaho National Engineering and Environmental Laboratory Report INEEL/EXT-98-00799 Rev.1, 1999;

https://inis.iaea.org/search/search.aspx?orig_q= $\mathrm{RN}: 32028722$

6- Liza Christine Grande, "Thermal Aspects of Using Alternative Nuclear Fuels in Supercritical Water-Cooled Reactors, "Master Thesis, Institute of Technology, Ontario University, 2010.

7- Leung, L., "Effect of CANDU bundle geometry variation on dryout power," Proc.of ICONE Conf. 16. Paper \#48827, p.8. Orlando, Florida, USA: ASME,2008.

8- Thermo physical Properties database of materials for light water reactors and heavy water reactors, International Atomic Energy Agency, Vienna, Austria (2005).

9- Lisa Grande, Bryan Villamere, Adrianexy Rodriguez-Prado, Sally Mikhael, Leyland Allison and Igor Pioro.,"Some Thermal Aspects of Using Thoria Fuel in SuperCritical WaterCooled Nuclear Reactors,'Proc. of the 17th International Conf. of Nuclear Engineering ICONE17. Brussels, Belgium,July 12-16,2009.

10- Bishop, A., Sandberg, R., \& Tong, L.,"Forced convection heat transfer to water at near-critical temperatures and super-critical pressures," Atomic Power Division. Pittsburgh, PA, USA: Westinghouse Electric Corporation, (1964).

11- H.S. Swenson, J.R. Carver, and C.R. Kakarala., "Heat transfer to supercritical water in smooth-bore tubes, Journal of Heat Transfer," 87 (4) (1965).

12- Naidin, M., Mokry, S., Pioro, I., Duffey, R., and Zirn, "U. SCW NPPs: Layouts and Thermodynamic Cycles," Proc. of Int. Conf. of Nuclear Energy for New Europe, Bled, Slovenia, Sep. 14-17, 2009.

13- Eugene Saltanov., "Steam-Reheat Option for Supercritical Water Cooled Reactors. Ontario," Ontario Univ; 2010. 